\title{
Ferromagnetic Co-Ni-Al Shape Memory Alloys with $\beta+\gamma$ Two-Phase Structure
}

\author{
Yuuki Tanaka $^{1, *}$, Toshihiro Ohmori ${ }^{1, *}$, Katsunari Oikawa ${ }^{2}$, Ryosuke Kainuma ${ }^{1}$ and Kiyohito Ishida ${ }^{1}$ \\ ${ }^{1}$ Department of Materials Science, Graduate School of Engineering, Tohoku University, Sendai 980-8579, Japan \\ ${ }^{2}$ National Institute of Advanced Industrial Science and Technology, Tohoku Center, Sendai 983-8551, Japan
}

The effects of the introduction of the $\gamma$ (A1) phase into the $\beta$ (B2) phase on the mechanical and shape memory properties in ferromagnetic Co-Ni-Al shape memory alloys with the $\beta+\gamma$ two-phase structure were investigated by cold-rolling, tensile tests, and bending tests. The mechanical properties were found to be improved with an increase in the volume fraction of the $\gamma$ phase, and Co-33 at\% Ni-26 at $\% \mathrm{Al}$ alloy with $V_{\gamma}=36 \%$ exhibited excellent cold workability with a critical reduction ratio of $40 \%$. Although the degree of shape recovery decreases with an increase in the volume fraction of the $\gamma$ phase, it can be enhanced by training. Since two-phase $\beta+\gamma \mathrm{Co}-\mathrm{Ni}$-Al alloys have several advantages such as cost efficiency and workability, this alloy system is considered as being a new type of ferromagnetic shape memory alloys (FSMAs).

(Received September 19, 2003; Accepted December 3, 2003)

Keywords: ferromagnetic shape memory alloys, two-phase $\beta+\gamma$ cobalt-nickel-aluminum alloy

\section{Introduction}

Recently, ferromagnetic shape memory alloys (FSMAs), which hold promise as a new type of magnetic field controlled actuator exhibiting large recoverable strain and rapid response, have received considerable attention since they exhibit a giant magnetostriction by applied a magnetic field. Numerous candidate systems for the FSMAs have been reported including $\left.\mathrm{Ni}_{2} \mathrm{MnGa},{ }^{1-3)} \mathrm{Ni}_{2} \mathrm{MnAl},{ }^{4-6)} \mathrm{Fe}-\mathrm{Pd},{ }^{7,8}\right)$ $\mathrm{Fe}_{3} \mathrm{Pt},{ }^{9)} \mathrm{CoNiGa},{ }^{10,11)}$ and $\mathrm{NiGaFe}^{12,13)}$ systems. However, these alloys have several problems, such as extreme brittleness in the polycrystalline state and the high cost of constitute elements, which restrict their practical applications.

It is known that the $\beta$ (B2) phase in the $\mathrm{Co}-\mathrm{Ni}-\mathrm{Al}$ system undergoes a thermoelastic martensitic transformation from B2 to $\mathrm{L} 1_{0}$ structure. ${ }^{14)}$ Recently, the present authors have found that the $\beta$ phase in the Co-rich $\mathrm{Co}-\mathrm{Ni}-\mathrm{Al}$ alloy undergoes a martensitic transformation in the ferromagnetic state. ${ }^{15)}$ The composition range of FSMAs is located near the $\beta+\gamma$ (A1) two-phase region, and the $\beta+\gamma$ two-phase FSMAs in the Co-Ni-Al system are characterized by good ductility. ${ }^{10)}$

However, the quantitative effects of the $\gamma$ phase on the mechanical and shape memory properties have not yet been clarified. In the present study, $\beta+\gamma$ two-phase $\mathrm{Co}-\mathrm{Ni}-\mathrm{Al}$ FSMAs were investigated.

\section{Experimental Procedures}

$\beta+\gamma$ two-phase Co-Ni-Al alloys, Co-(33 to 33.5)at $\% \mathrm{Ni}-$ (23 to 28$)$ at $\% \mathrm{Al}$ were prepared by melting pure Co (99.9\%), $\mathrm{Ni}(99.9 \%)$ and $\mathrm{Al}(99.7 \%)$ in an induction furnace under an argon atmosphere. The obtained ingots were hot-rolled at about $1573 \mathrm{~K}$ in the $\beta+\gamma$ two-phase state up to a thickness of about $2 \mathrm{~mm}$ and heat-treated at $1523 \mathrm{~K}$ to $1573 \mathrm{~K}$ for 3.6 to $4.8 \mathrm{ks}$ followed by quenching in ice water. The specimens are designated as $23 \mathrm{Al}$ to $28 \mathrm{Al}$ as shown in Table 1.

The microstructures of the specimens were examined by optical microscopy. The compositions of the $\beta$ and $\gamma$ phases were determined by energy dispersion X-ray spectroscopy (EDX) using a standard calibration method, and the volume fractions of the $\gamma$ phase were determined on the basis of these experimental data by the lever rules. The martensitic transformation temperatures were determined by differential scanning calorimetry (DSC) at cooling and heating rates of $10 \mathrm{~K} / \mathrm{min}$. The Curie temperature, $T_{\mathrm{c}}$, was measured by using a vibrating sample magnetometer (VSM) and defined as the minimum point of the temperature derivative of magnetization at the field strength $H$ of $0.04 \mathrm{MAm}^{-1}$. The volume fraction of the $\gamma$ phase $V_{\gamma}$, martensitic transformation starting temperature, $M_{\mathrm{s}}$, reverse transformation finishing temperature, $A_{\mathrm{f}}$, and Curie temperature, $T_{\mathrm{c}}$, in all the specimens after annealing at 1523 to $1573 \mathrm{~K}$ are listed in Table 1.

Table 1 Composition, volume fraction of the $\gamma$ phase, martensitic transformation and Curie temperatures and grain size of $\beta$ phase in present alloys.

\begin{tabular}{|c|c|c|c|c|c|c|c|}
\hline $\begin{array}{c}\text { Alloy } \\
\text { designation }\end{array}$ & $\begin{array}{c}\text { Alloy } \\
\text { composition }\end{array}$ & $\begin{array}{c}\text { Annealing } \\
\text { temperature } \\
T / \mathrm{K}\end{array}$ & $\begin{array}{c}\text { Volume fraction } \\
\text { of } \gamma \text { phase } \\
V_{\gamma} / \%\end{array}$ & $\begin{array}{l}M_{\mathrm{S}} \\
/ \mathrm{K}\end{array}$ & $\begin{array}{l}A_{\mathrm{f}} \\
/ \mathrm{K}\end{array}$ & $\begin{array}{l}T_{\mathrm{c}} \\
/ \mathrm{K}\end{array}$ & $\begin{array}{c}\text { Grain size } \\
\text { of } \beta \text { phase } \\
d / \mu \mathrm{m}\end{array}$ \\
\hline $28 \mathrm{Al}$ & $\mathrm{Co}-33.5$ at $\% \mathrm{Ni}-28$ at $\% \mathrm{Al}$ & 1533 & 7 & 247 & 290 & 297 & 788 \\
\hline $27 \mathrm{Al}$ & $\mathrm{Co}-33.5$ at $\% \mathrm{Ni}-27$ at $\% \mathrm{Al}$ & 1523 & 18 & 249 & 290 & 321 & 560 \\
\hline 26Al & $\mathrm{Co}-33$ at $\% \mathrm{Ni}-26$ at $\% \mathrm{Al}$ & 1553 & 24 & 253 & 294 & 324 & 112 \\
\hline $25 \mathrm{Al}$ & Co-33 at $\% \mathrm{Ni}-25$ at $\% \mathrm{Al}$ & 1573 & 31 & 257 & 297 & 302 & 94 \\
\hline $24 \mathrm{Al}$ & $\mathrm{Co}-33$ at $\% \mathrm{Ni}-24$ at $\% \mathrm{Al}$ & 1573 & 42 & 256 & 298 & 310 & 54 \\
\hline $23 \mathrm{Al}$ & $\mathrm{Co}-33$ at $\% \mathrm{Ni}-23$ at $\% \mathrm{Al}$ & 1573 & 52 & 246 & 289 & 293 & 29 \\
\hline
\end{tabular}

*Graduate Student, Tohoku University 
The mechanical properties were examined by tensile testing at room temperature, and the crosshead speed was $0.5 \mathrm{~mm} / \mathrm{min}$. The critical reduction ratio by cold-rolling is defined as $\left(t_{0}-t_{\min }\right) / t_{0} \times 100 \%$, where $t_{0}$ is the initial thickness and $t_{\min }$ corresponds to the minimum thickness just before a crack is introduced in the specimen. The shape memory (SM) property was evaluated by the conventional bending test, as described in our previous paper. ${ }^{16)}$ The bending specimen was $30 \mathrm{~mm}$ in length, $3 \mathrm{~mm}$ in width and $0.15 \mathrm{~mm}$ in thickness.

\section{Results and Discussion}

\subsection{Microstructures}

Figure 1 shows the $\beta+\gamma$ two-phase microstructures of 28Al, 26Al and 23Al, where the volume fraction of the $\gamma$ phase is about $7 \%, 25 \%$ and $52 \%$, respectively. It can be seen that there are $\gamma$ phase precipitates in both the matrix and at the boundaries of the $\beta$ phase in each specimen, and that the volume fraction of the $\gamma$ phase increases with decreasing $\mathrm{Al}$ content. The lower Al alloy with a high amount of $\gamma$ phase content shows smaller $\beta$ grains. This result can be explained as being due to the pinning effect of the grain growth resulting from the precipitation of the $\gamma$ phase.

\subsection{Mechanical properties}

Results of the critical reduction ratio evaluated by coldrolling in $\mathrm{Co}-33.5$ at $\% \mathrm{Ni}-27$ at\% Al and $\mathrm{Co}-33 \mathrm{at} \% \mathrm{Ni}-26$ at $\% \mathrm{Al}$ alloys with several $V_{\gamma}$ are listed in Table 2, together with the volume fraction $V_{\gamma}$, where $V_{\gamma}$ was controlled by the annealing condition. Concomitant with lowering of the annealing temperature, the $\beta+\gamma$ two-phase region in the $\mathrm{Co}-\mathrm{Ni}-\mathrm{Al}$ system widens and, therefore, the volume fraction of the $\gamma$ phase increases. ${ }^{13)}$ Figure 2 shows the critical reduction ratio by cold-rolling as a function of the volume fraction of the $\gamma$ phase. The cold workability is proportionally improved with increasing volume fraction of the $\gamma$ phase, and the 26Al alloy with $V_{\gamma}=36 \%$ exhibits the most excellent cold workability with a critical reduction ratio of $40 \%$.

Thus, the $\beta+\gamma$ two-phase Co-Ni-Al alloys can be fabricated into various favorable shapes such as sheets and wires by thermomechanical processes including cold-working. Figure 3 shows the appearance of a Co-33at\% Ni26 at\% Al alloy thin sheet with a thickness of $150 \mu \mathrm{m}$. This sheet was prepared by multiple cold-rolling for each reduction ratio of 30 to $35 \%$ with intermediate annealing at $1273 \mathrm{~K}$ for $1.8 \mathrm{ks}$.

Stress-strain curves of specimens $23 \mathrm{Al}$ to $28 \mathrm{Al}$ at room temperature are shown in Fig. 4, and the mechanical properties extracted from these curves are plotted against the volume fraction of the $\gamma$ phase in Fig. 5. It is seen that the mechanical properties are strongly influenced by the volume fraction of the $\gamma$ phase and improved with an increase of the volume fraction of the $\gamma$ phase. It is noteworthy that the mechanical properties of specimens $28 \mathrm{Al}$ and $27 \mathrm{Al}$ are considerably poor in comparison with that of specimen $26 \mathrm{Al}$ and that the critical fraction of the $\gamma$ phase from brittle to ductile is in the vicinity of $20 \%$ between specimens $26 \mathrm{Al}$ and 27Al. This result may also be attributed to the appreciable difference of the $\beta$-grain size, as listed in Table 1 .
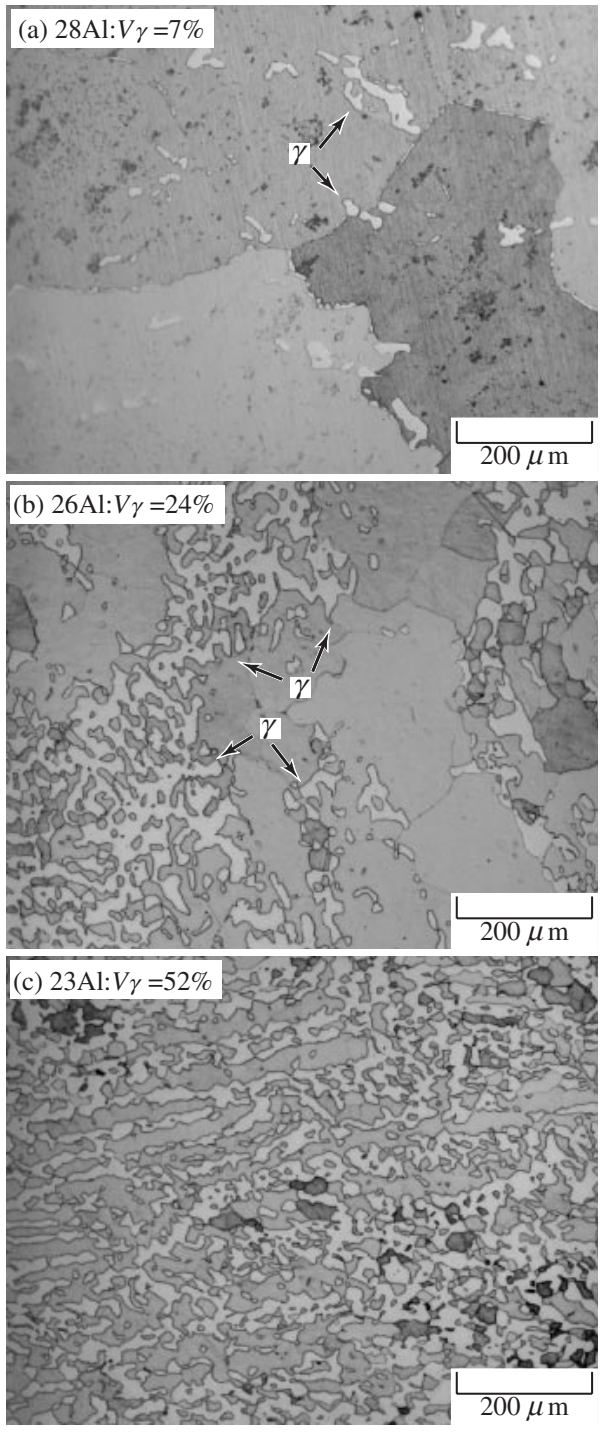

Fig. 1 Microstructures of $\beta+\gamma$ two-phase Co-Ni-Al alloys. (a) 28Al: $V_{\gamma}=7 \%$, (b) 26Al: $V_{\gamma}=24 \%$ and (c) $23 \mathrm{Al}: V_{\gamma}=52 \%$.

\subsection{SM properties}

The SME by the bending tests is demonstrated in Fig. 6. Figure 6(a) shows a thin plate of $\mathrm{Co}-33$ at $\% \mathrm{Ni}-26$ at $\% \mathrm{Al}$ annealed at $1626 \mathrm{~K}$ for $1.8 \mathrm{ks}$, with dimensions of $0.25 \mathrm{~mm} \times$ $3 \mathrm{~mm} \times 45 \mathrm{~mm}$. The volume fraction of the $\gamma$ phase of this specimen is about $18 \%$ and the transformation temperatures of $M_{\mathrm{s}}, A_{\mathrm{f}}$, and $T_{\mathrm{c}}$ were $316 \mathrm{~K}, 350 \mathrm{~K}$ and $347 \mathrm{~K}$, respectively. The thin plates were bent to realize a surface strain of $2 \%$ at $293 \mathrm{~K}$ below $M_{\mathrm{s}}$ (Fig. 6(b)). On heating to $423 \mathrm{~K}$ above $A_{\mathrm{f}}$, the SME appears and the degree of shape recovery in the specimen is $76 \%$ (Fig. 6(c)).

Figure 7 shows the shape recovery obtained by the bending test as a function of the volume fraction of the $\gamma$ phase. The degree of shape recovery decreases with increasing volume fraction of the $\gamma$ phase. It is shown that the shape recovery drastically decreases at about $V_{\gamma}=20 \%$. This drastic decrease might be related to the grain-size effect. With regard to the effect of grain size on the SM properties, as reported by Dvorak and Hawbolt, ${ }^{17)}$ large grain size results in a good SM effect. The $\beta$-grain size of $28 \mathrm{Al}$ and $27 \mathrm{Al}$ is much larger than that of $26 \mathrm{Al}-23 \mathrm{Al}$ as shown in Table 1 , and the $\beta$ 
Table 2 Volume fraction of the $\gamma$ phase and cold rolling reduction in Co33.5 at $\% \mathrm{Ni}-27$ at $\% \mathrm{Al}$ and $\mathrm{Co}-33 \mathrm{at} \% \mathrm{Ni}-26$ at\% $\mathrm{Al}$ alloys after various annealing.

\begin{tabular}{|c|c|c|c|}
\hline $\begin{array}{c}\text { Alloy } \\
\text { composition }\end{array}$ & $\begin{array}{c}\text { Annealing } \\
\text { temperature } \\
T / \mathrm{K}\end{array}$ & $\begin{array}{c}\text { Volume fraction } \\
\text { of } \gamma \text { phase } \\
V_{\gamma} / \%\end{array}$ & $\begin{array}{c}\text { Critical } \\
\text { reduction ratio } \\
1 \%\end{array}$ \\
\hline \multirow{2}{*}{$\mathrm{Co}-33.5$ at $\% \mathrm{Ni}-27$ at $\% \mathrm{Al}$} & 1623 & 7 & 8 \\
\hline & 1573 & 13 & 17 \\
\hline \multirow{5}{*}{$\mathrm{Co}-33$ at $\% \mathrm{Ni}-26$ at $\% \mathrm{Al}$} & 1623 & 18 & 19 \\
\hline & 1573 & 22 & 28 \\
\hline & 1473 & 26 & 35 \\
\hline & 1373 & 30 & 38 \\
\hline & 1273 & 36 & 40 \\
\hline
\end{tabular}

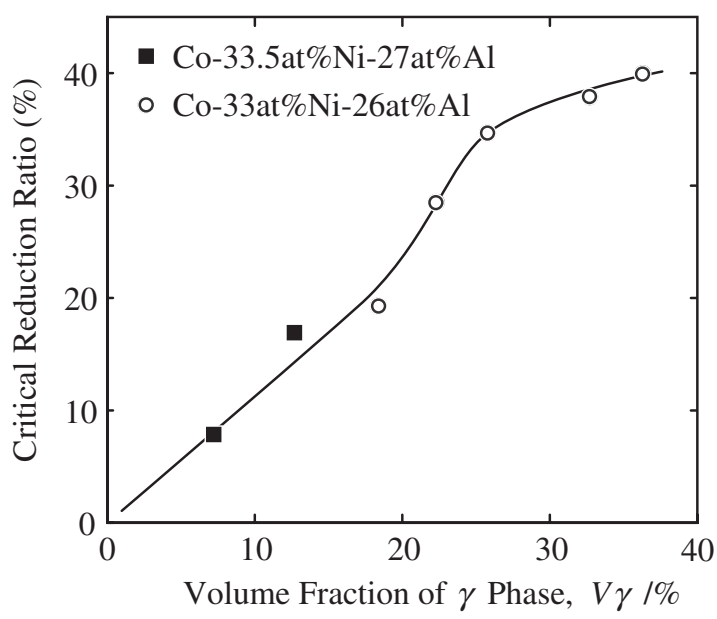

Fig. 2 Effect of $\gamma$ phase volume fraction on the cold workability.

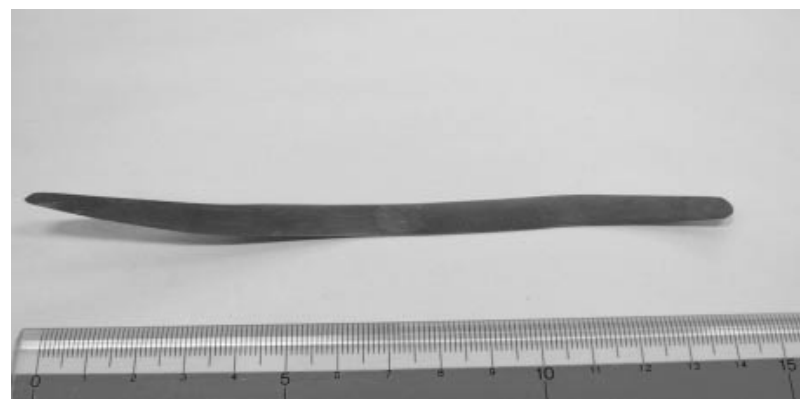

Fig. 3 Appearance of thin plate of Co-34 at $\% \mathrm{Ni}-26$ at\% Al alloy with a thickness of about $150 \mu \mathrm{m}$ after multiple cold-rolling down to a reduction ratio of $30-35 \%$ and annealing at $1273 \mathrm{~K}$ for $1.8 \mathrm{ks}$.

grain structure of specimens $28 \mathrm{Al}$ and $27 \mathrm{Al}$ should be of a columnar type, because the grain size is several times larger than the thickness of specimen. Since the constraint of grains in $28 \mathrm{Al}$ and $27 \mathrm{Al}$ is supposed to be smaller than that of grains in $26 \mathrm{Al}-23 \mathrm{Al}$, a high ratio of shape recovery was obtained in the specimens of $28 \mathrm{Al}$ and $27 \mathrm{Al}$.

Although $\beta+\gamma$ Co-Ni-Al two-phase alloys exhibit the SME incompletely at the first SME cycle, further plastic deformation is hardly accumulated after the second cycle. Figure 6(d) shows a specimen that was cooled to $293 \mathrm{~K}$ and bent to the same curvature again as in the first deformation in Fig. 6(b). On subsequent heating to $423 \mathrm{~K}$, no further residual strain was observed (Fig. 6(e)), which means that an almost

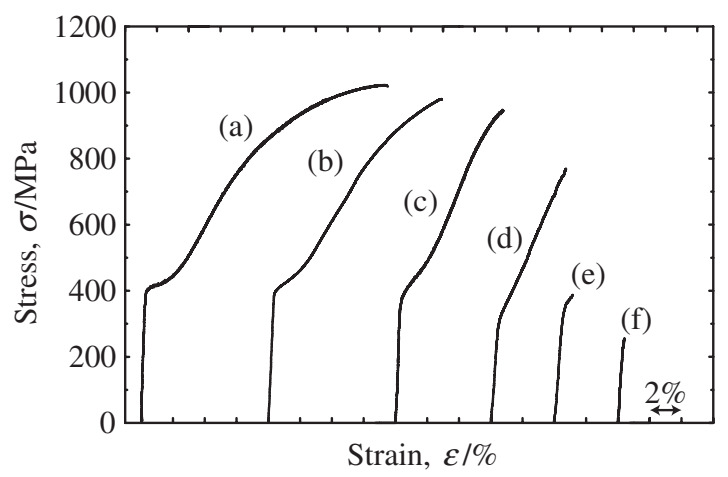

Fig. 4 Stress-strain curves of (a) 23Al: $V_{\gamma}=52 \%$, (b) $24 \mathrm{Al}: V_{\gamma}=42 \%$, (c) $25 \mathrm{Al}: V_{\gamma}=31 \%$, (d) $26 \mathrm{Al}: V_{\gamma}=24 \%$, (e) $27 \mathrm{Al}: V_{\gamma}=18 \%$ and (f) 28Al: $V_{\gamma}=7 \%$.

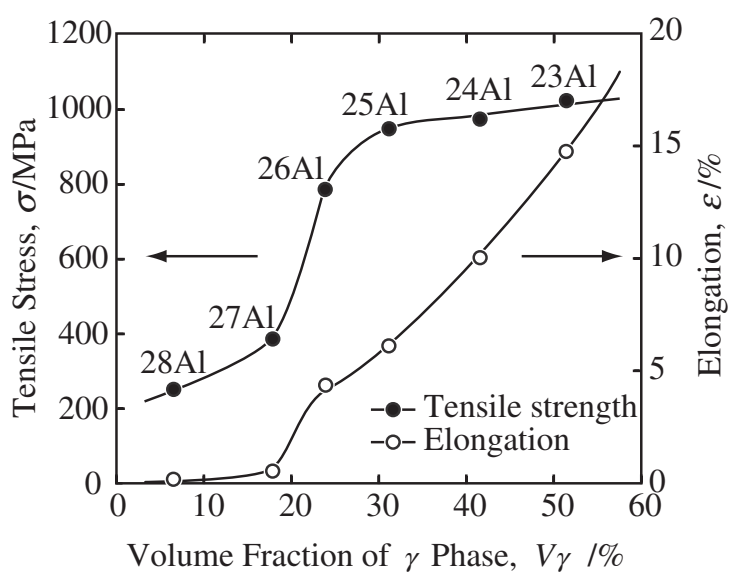

Fig. 5 Effect of $\gamma$ volume fraction on the tensile properties at room temperature.

perfect SME is achieved by training in $\beta+\gamma$ Co-Ni-Al twophase alloys. This effect has also been reported in two-phase $\beta+\gamma$ Ni-Al-Fe shape memory alloys. ${ }^{16)}$ This result suggests that pre-deformation would be an effective method to enhance the degree of shape recovery in two-phase $\beta+\gamma$ Co-Ni-Al alloys, where the fresh slip deformation was suppressed in the second SME cycle through the introduction of dislocations, which raise the critical slip stress in the first cycle.

Subsequently, on cooling to $293 \mathrm{~K}$, the shape of the plate changed spontaneously (Fig. 6(f)), and then reversible shape change occurred with cooling and heating, namely, a twoway SME appears.

For practical use of shape memory alloys, it is important to know the recovery stress of the specimen associated with the SME on heating. The method to measure the recovery stress is described as follows. A rectangular specimen of Co33 at $\% \mathrm{Ni}-26$ at $\% \mathrm{Al}$ annealed at $1626 \mathrm{~K}$ for $1.8 \mathrm{ks}$ with an $18 \mathrm{vol} \% \gamma$ phase and a thickness of about $0.5 \mathrm{~mm}$ was loaded in tension to a strain of about $1 \%$ at $293 \mathrm{~K}$ below $M_{\mathrm{s}}$, and then unloaded. On heating of the deformed specimen with both ends fixed, the reverse transformation proceeded and the extension stress increased, a maximum stress of about $134 \mathrm{MPa}$ was obtained by heating to $423 \mathrm{~K}$ above $A_{\mathrm{f}}$. This value is considered as the recovery stress of this specimen.

In conclusion, since two-phase $\beta+\gamma \mathrm{Co}-\mathrm{Ni}-\mathrm{Al}$ alloys not 


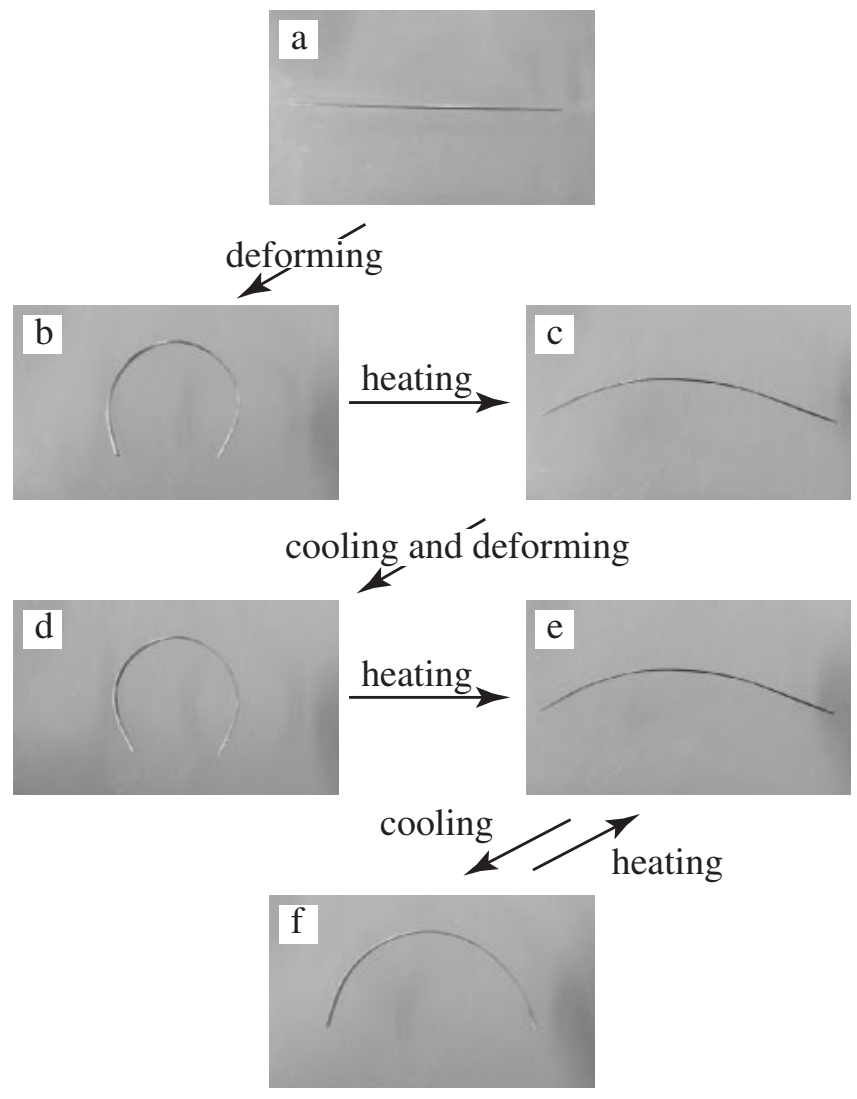

Fig. 6 Demonstration of SME. (a) thin plate of Co-34 at $\% \mathrm{Ni}-26$ at $\% \mathrm{Al}$ with $V_{\gamma}=18 \%$, (b) deformed at $293 \mathrm{~K}$, (c) heated to about $423 \mathrm{~K}$, (d) cooled to $293 \mathrm{~K}$ and deformed, (e) heated to about $423 \mathrm{~K}$ and (f) cooled to $293 \mathrm{~K}$.

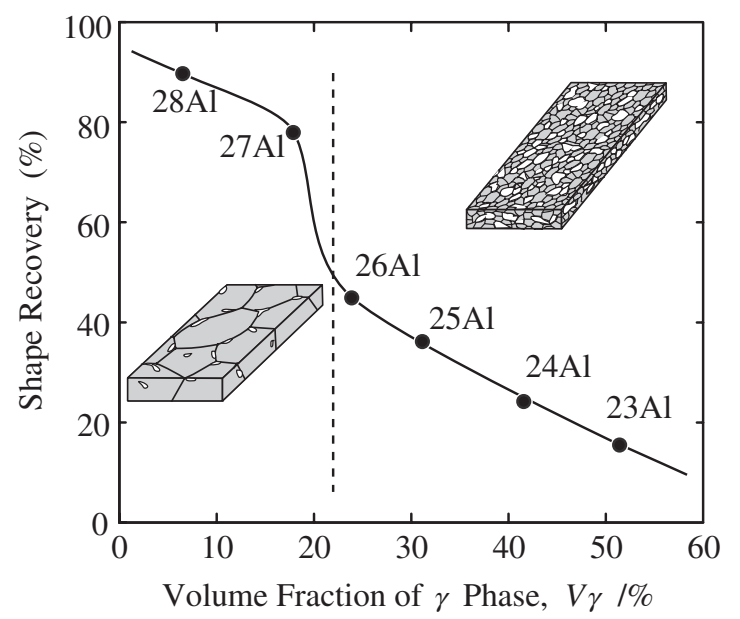

Fig. 7 Effect of $\gamma$ volume fraction on shape recovery.

only have the advantage of cost effucuency and workability compared with other FSMEs but also exhibit a perfect shape memory effect by training, this alloy system is considered to be a new type of FMSAs and to have the high potential for practical applications.

\section{Conclusions}

The effect of the introduction of the $\gamma$ phase on the cold workability, the mechanical properties and the shape memory properties in $\mathrm{Co}-\mathrm{Ni}$-Al alloys with the $\beta+\gamma$ two-phase structure were investigated. The results obtained are as follows.

(1) The cold workability of the Co-Ni-Al $\beta$ based alloy is improved with an increase in the volume fraction of the $\gamma$ phase. The specimens with a 36 vol $\% \gamma$ phase exhibit excellent cold workability of about $40 \%$ in critical reduction ratio of cold-rolling. $\beta+\gamma$ two-phase $\mathrm{Co}-\mathrm{Ni}$ $\mathrm{Al}$ alloys can be fabricated in various shapes such as thin plates and wires through thermomechanical treatment.

(2) The tensile strength and elongation are increased by increasing the volume fraction of the $\gamma$ phase due to the decrease of $\beta$ phase grain size.

(3) The shape recovery decreases with increasing $\gamma$ phase volume fraction. However, a perfect shape memory effect is achieved after one cycle of training. In addition, the two-way shape memory effect can be obtained.

\section{Acknowledgments}

This study was supported by Grant-in-Aids for Scientific Research from the Ministry of Education, Culture, Sports, Science and Technology, Japan and by Industrial Technology Research Grant Program in ' 02 from New Energy and Industrial Technology Development Organization (NEDO) Japan.

\section{REFERENCES}

1) K. Ullakko, J. K. Huang, C. Kanter, V. V. Kokorin and R. C. O’Handley: Appl. Phys. Lett. 69 (1996) 1966-1968.

2) S. J. Murray, M. Marioni, A. Kukla, J. Robinson, R. C. O'Handley and S. M. Allem: J. Appl. Phys. 87 (2000) 5774-5776.

3) S. J. Murray, M. Marioni, S. M. Allen and R. C. O'Handley: Appl. Phys. Lett. 77 (2000) 886-888.

4) F. Gejima, Y. Sutou, R. Kainuma and K. Ishida: Metall. Mater. Trans. A 30 (1999) 2721-2723.

5) R. Kainuma. F. Gejima, Y. Sutou, I. Ohnuma and K. Ishida: Mater. Trans., JIM 41 (2000) 943-949.

6) A. Fujita, K. Fukamichi, F. Gejima, R. Kainuma and K. Ishida: Appl. Phys. Lett. 77 (2000) 3054-3056.

7) R. D. James and M. Wuttig: Philos. Mag. A 77 (1998) 1273-1299.

8) Y. Furuya, N. W. Hangood, H. Kimura and T. Watanabe: Mater. Trans., JIM 39 (1998) 1248-1254.

9) T. Kakeshita, T. Takeuchi, T. Fukuda, T. Saburi, R. Oshima, S. Muto and K. Kishio: Mater. Trans., JIM 41 (2000) 882-887.

10) K. Oikawa, T. Ota, F. Gejima, T. Ohmori, R. Kainuma and K. Ishida: Mater. Trans. 42 (2001) 2472-2475.

11) M. Wuttig, J. Li and C. Craciunescu: Scr. Mater. 44 (2001) 2393-2397.

12) K. Oikawa, T. Ota, T. Ohmori, Y. Tanaka, H. Morito, A. Fujita, R. Kainuma, K. Fukamichi and K. Ishida: Appl. Phys. Lett. 81 (2002) 5201-5203.

13) Z. H. Liu, M. Zhang, Y. T. Cui, Y. Q. Zhou, W. H. Wang, G. H. Wu, X. X. Zhang and G. Xiao: Appl. Phys. Lett. 82 (2003) 424-426.

14) R. Kainuma, M. Ise, C. C. Jia, H. Ohtani and K. Ishida: Intermetallics 4 (1996) S151-158.

15) K. Oikawa, L. Wulff, T. Iijima, F. Gejima, T. Ohmori, A. Fujita, K. Fukamichi, R. Kainuma and K. Ishida: Appl. Phys. Lett. 79 (2001) 3290-3292.

16) R. Kainuma, K. Ishida and T. Nishizawa: Metall. Trans. A. 23A (1992) 1147-1153.

17) I. Dvorak and E. B. Hawbolt: Metall. Trans. A. 6A (1976) 95-99. 